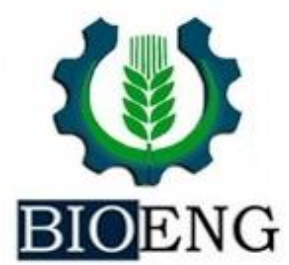

\title{
MÉTODOS COMPLEMENTARES PARA TRATAMENTO DE RESÍDUOS PROVENIENTES DA SUINOCULTURA
}

UNESP - Universidade Estadual Paulista, FCE, Departamento de Engenharia de Biossistemas, Tupã, SP, Brasil

Article history: Received 12 November 2019; Received in revised form 20 November 2019; Accepted 30 November 2019; Available online 05 December 2019.

\begin{abstract}
RESUMO
O contínuo crescimento da população mundial está diretamente associado à necessidade de incrementar a produção de alimentos, tanto de origem vegetal, quanto animal, contudo, este incremento resulta em um aumento na geração de resíduos das cadeias produtivas. Conscientizar os produtores de suínos para aumentar a produção e reduzir os efeitos nocivos ao ambiente se torna necessário, visto que, a suinocultura é uma atividade agropecuária que causa grande impacto ambiental. $\mathrm{O}$ objetivo deste trabalho foi realizar o tratamento primário dos resíduos provenientes da suinocultura após o processo de biodigestão. Dentre os tratamentos realizados pode-se destacar que o tratamento 2 contendo sulfato de alumínio obteve uma melhor resposta na remoção da demanda química de oxigênio (DQO) quando comparado aos demais tratamentos. Os resultados são de elevada importância, pois refletem na produtividade e, consequentemente, na rentabilidade, além de minimizar os impactos ambientais.
\end{abstract}

Palavras-chave: suinocultura; impactos ambientais; agentes coagulantes; análises físicoquímicas

\section{ADDITIONAL METHODS FOR SWINE WASTE TREATMENT}

\begin{abstract}
The continuous increase in the world population is associated with a distinct need to increase food production, both of vegetable and animal origin, however, this increase results in greater generation of waste in the production chains. Awareness of swine producers to rise production and reduce harmful effects on the environment becomes necessary, since swine farming is an agricultural activity that causes great environmental impact. The objective of this work was to carry out the primary treatment of swill manure after passing through the biodigester. Among the treatments used, we can highlight that the treatment 2 containing aluminum sulphate obtained a better response in the removal of chemical oxygen demand (COD) when compared to the other treatments. Given the importance of these results since they reflect on productivity and, consequently, on profitability in addition to minimizing environmental impacts.
\end{abstract}

Keywords: swine; environmental impacts; coagulant agents; physicochemical analysis 


\section{INTRODUÇÃO}

A carne suína é umas das mais produzidas e consumidas no Brasil e no mundo. $\mathrm{O}$ Brasil encontra-se em $4^{\circ}$ lugar no ranking mundial em carne suína com 3,73 milhões de toneladas, destas 732,9 mil toneladas foram exportadas, quando comparado ao ano anterior o país obteve $32 \%$ de aumento na exportação da carne suína (MIELE; SANDI, 2016).

Segundo o IBGE (2018) em 2017 o Brasil bateu o recorde na criação de porcos com 43,19 milhões de cabeças com relação a 2016, obteve um aumento na produção de $2,2 \%$, ficando com maior produtividade de suínos o estado de Santa Catarina, possuindo $26,6 \%$ do abate em relação ao país todo.

A qualidade da carne suína está relacionada diretamente com o bem-estar animal, comprovando assim a importância do mesmo, uma vez que animais sujeitos a longos períodos de estresse tendem a ter o $\mathrm{pH}$ da carne elevado, favorecendo dessa forma o desenvolvimento dos microrganismos que degradam a carne (LUDTKE et al., 2010).

O conceito de bem-estar dos animais adotado mundialmente baseia-se no respeito a cinco liberdades, que são: fisiológica (livre de sede, fome e mánutrição); ambiental (edificações adaptadas); sanitária (livre de fratura e doença); comportamental (livre para expressar seu comportamento normal); e psicológica (livre de medo e ansiedade) (SANTOS, 2004).

De acordo com Straus e Menezes (1993) as questões ambientais promovem cada vez mais o interesse e a preocupação envolvendo as atividades agroindustriais. $\mathrm{O}$ aumento da produção dos resíduos provoca impactos ambientais, de maneira que a taxa de geração é consideravelmente maior que a taxa de degradação. Assim, torna-se necessário a redução, reciclagem e o reaproveitamento dos resíduos gerados pelo homem e pelos animais, com o principal objetivo de recuperar matéria e produzir energia a partir deles.
Fiori et al. (2008) dizem que a compostagem, tanques aeróbicos e biodigestores são alguns exemplos de tratamentos capazes de minimizar os impactos causados pelos resíduos, sendo utilizados para outros fins como produção de energia e fertilizantes agrícolas.

A agroindústria é um dos principais segmentos para a economia brasileira, com importância tanto para o abastecimento interno quanto para o desempenho exportador do Brasil. Porém, devido à proximidade das agroindústrias aos centros urbanos, acabam produzindo grandes quantidades de resíduos sólidos e líquidos onde, na maioria dos casos, são levados a aterros sanitários, diminuindo a sua vida útil ou estocadas próximas às áreas de produção, gerando problemas sanitários e ambientais

CHERNICHARO, 2005).

(LAUCENA;

Em grande parte da sua produção os resíduos podem ser transformados em insumos agrícolas e utilizados nas áreas que são gerados para aumentar a produção e potencializar o desempenho das culturas. Isso significa que proporcionam aos agricultores uma melhor qualidade do solo e diminuição dos custos. Giffoni e Lange (2005) afirmam que a reciclagem e a reutilização dos resíduos sejam uma alternativa capaz de contribuir com diferentes tipos de matéria-prima, diminuindo os custos finais dos setores agroindustriais e contribuindo para a preservação do ambiente.

Sendo assim, o objetivo geral desse trabalho foi propor, desenvolver e avaliar o tratamento primário dos resíduos provenientes da suinocultura após passagem pelo biodigestor. Visando atingir o objetivo geral, justificam-se ainda como objetivos específicos: realizar as análises físico-químicas antes e após os tratamentos; construir um filtro com o intuito de aumentar a eficiência na retenção de sólidos suspensos; simular algumas etapas do tratamento convencional de uma estação de tratamento 
de resíduos, sendo elas a decantação, coagulação, floculação e filtração e

\section{PROCEDIMENTOS EXPERIMENTAL}

\section{Caracterização da área de coleta}

O presente trabalho foi realizado no Sítio Estrela, localizado na área rural do distrito de Parnaso pertencente ao município de Tupã, São Paulo (21 '56"34' $\mathrm{S}$ e $\left.50^{\circ} 24^{\prime \prime} 59^{\prime} \mathrm{O}\right)$ apresentando uma área total de 20 alqueires.

A atividade desenvolvida no local caracteriza-se como familiar, onde se predomina a criação de suínos. Além da atividade suinícola, os proprietários são responsáveis pela criação de bovinos e ovinos.

A criação de suínos no Sítio Estrela compreende as etapas de maternidade, creche, crescimento, terminação, abate e sangria. Os animais da granja são provenientes do cruzamento entre as raças suínas de landrace x large white.

Visando minimizar os impactos ambientais e descartar os resíduos resultantes da atividade principal de maneira correta, os proprietários investiram no ano de 2014 cerca de $\mathrm{R} \$ 300.000,00$ mil na instalação de um biodigestor. $\mathrm{O}$ biodigestor além de produzir energia elétrica é responsável pela produção de biofertilizante utilizado na irrigação da pastagem local.

O resíduo bruto proveniente da suinocultura foi coletado após passagem pelo biodigestor, em recipiente adequado e armazenado sob refrigeração.

\section{Análises físico-químicas}

É importante salientar que as análises físico-químicas foram realizadas antes e depois dos tratamentos.

As medidas de $\mathrm{pH}$, condutividade elétrica (CE), sólidos totais dissolvidos (STD) e oxigênio dissolvido (OD) foram realizadas por meio de um Analisador Multiparâmetro SENSORDIRECT 150, Lovibond Water Testing, usando um eletrodo para medidas de $\mathrm{pH}$, um eletrodo para medidas de CE e STD e um eletrodo comparar o efeito de diferentes agentes coagulantes (químico e natural).

para medidas de OD. Todos os eletrodos foram calibrados previamente e a temperatura foi mantida constante em $25^{\circ} \mathrm{C}$ durante as análises.

A alcalinidade foi determinada empiricamente por titulação da amostra com uma solução padrão de ácido sulfúrico, usando fenolftaleína e alaranjado de metila como indicadores. A determinação de cloreto foi realizada utilizando a titulação argentométrica, com cromato de potássio $\left(\mathrm{K}_{2} \mathrm{CrO}_{4}\right)$ como indicador.

Sódio e potássio foram analisados em fotômetro de chama pelos métodos 3500-Na B e 3500-K B, respectivamente (APHA, 2012). A análise de cálcio foi realizada pelo método gravimétrico, utilizando ácido oxálico $1,0 \mathrm{~mol} / \mathrm{L} \mathrm{com}$ calcinação a $900^{\circ} \mathrm{C}$ durante 2 horas.

A Demanda Química de Oxigênio foi avaliada pelo método Colorimétrico de Refluxo Fechado (ASTM, 1995) em 600 $\mathrm{nm}$, usando espectrofotômetro UV-Vis (UV-1800, Shimadzu).

\section{Construção do filtro}

O filtro foi construído em um recipiente apropriado, acoplado com uma torneira, utilizando manta de drenagem, grades de contenção, areia fina, areia grossa, cascalhos e cerâmica.

\section{Tratamentos do resíduo}

O resíduo foi submetido ao um processo inicial de decantação e sedimentação natural por 10 minutos. $\mathrm{O}$ $\mathrm{pH}$ foi corrigido com hidróxido de cálcio 2\% para aumentar a eficiência dos coagulantes. Posteriormente, o efluente bruto foi separado em três béqueres contendo $100 \mathrm{~mL}$ de amostra bruta, sendo submetidos à etapa de coagulação com agitação magnética durante 10 minutos com diferentes agentes coagulantes, como mostra a tabela 1 . 
Após a etapa de coagulação, os efluentes foram submetidos à etapa de decantação por 30 minutos. Por fim, foi realizada a etapa de filtração.

Tabela 1- Agente coagulantes utilizados nos diferentes tratamentos

\begin{tabular}{|c|c|c|l|}
\hline & $\begin{array}{c}\text { Natureza do } \\
\text { coagulante }\end{array}$ & Agentes coagulantes & \multicolumn{1}{|c|}{ Alíquota } \\
\hline Tratamento 1 & Químico & Cloreto férrico & $\begin{array}{l}4 \mathrm{~mL} \mathrm{de} \mathrm{cloreto} \mathrm{férrico} \mathrm{1 \%} \mathrm{a} \\
\text { cada 100 mL de efluente bruto }\end{array}$ \\
\hline Tratamento 2 & Químico & Sulfato de alumínio & $\begin{array}{l}4 \mathrm{~mL} \mathrm{de} \mathrm{sulfato} \mathrm{de} \mathrm{alumínio} \mathrm{1 \%} \\
\text { a cada 100 mL de efluente bruto }\end{array}$ \\
\hline Tratamento 3 & Natural & Aloe Vera & $\begin{array}{l}40 \mathrm{~mL} \text { de aloe e vera em } 100 \mathrm{~mL} \\
\text { de efluente bruto }\end{array}$ \\
\hline
\end{tabular}

\section{RESULTADOS E DISCUSSÃO}

Durante a realização do presente estudo a primeira etapa observada foi o da decantação, tal processo ocorreu de forma satisfatória. Vesilind e Morgan (2011) explicam que nessa etapa as partículas mais pesadas que a água se sedimentam no fundo do recipiente, tal fato pode ser observado na Figura 1.

Após a adição do coagulante e da agitação, é possível visualizar a formação de flocos, como mostra a Figura 2. Vale ressaltar que os coagulantes químicos empregados provocaram a alteração química das partículas, permitindo assim a aglomeração e a formação de partículas maiores conhecidas como flocos (VESILIND; MORGAN, 2011). Porém, o coagulante natural não apresentou floculação visível. Corniciuc (2015) relata que a coagulação química é mais rápida, mais eficiente e mais utilizada quando comparada com os demais tipos, uma vez que força a reação a ocorrer.

De acordo com Vesilind e Morgan (2011) o objetivo da coagulação é "retirar da água os sólidos coloidais suspensos, produzindo partículas maiores que sedimentam imediatamente", ou seja, promove a remoção da turbidez orgânica e inorgânica.

Em seguida, ocorreu a etapa de decantação, a mesma acontece de forma simultânea à coagulação.

Por fim, realizou a etapa de filtração, como ilustra a Figura 3 e os resultados na Figura 4. Nessa etapa, ocorre a remoção das partículas ainda suspensas na amostra, ou seja, as partículas que não foram removidas durante a decantação.

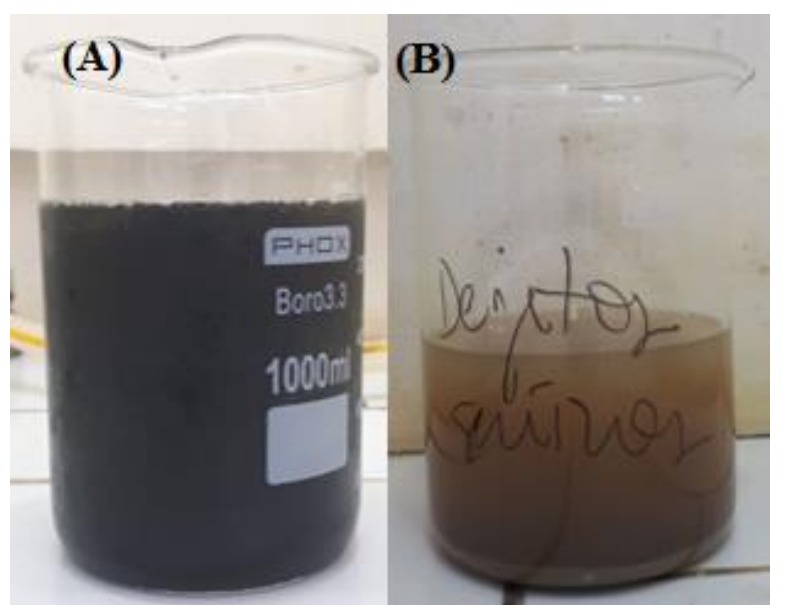

Figura 1. (A) Efluente bruto; (B) Efluente bruto após a decantação natural após 10 minutos em repouso. 


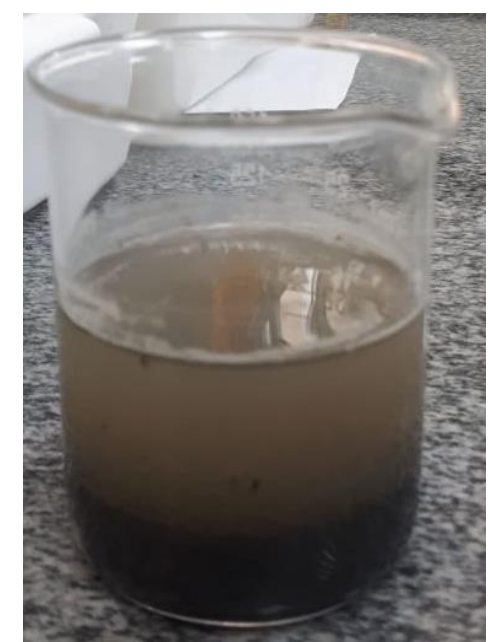

Figura 2- Formação de flocos após a adição do coagulante.

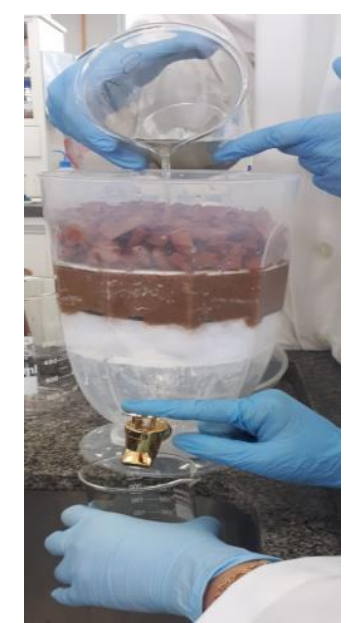

Figura 3- Etapa de filtração do efluente.

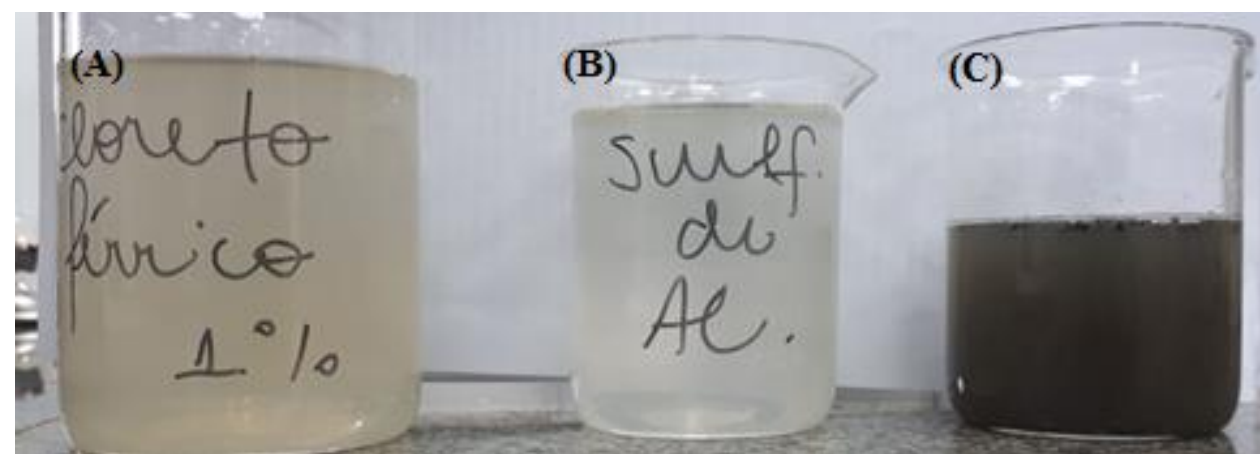

Figura 4 - Amostras do efluente após a etapa de filtração (A) cloreto férrico; (B) sulfato de alumínio; (C) resíduo bruto.

A tabela 2 apresenta os dados obtidos através das análises físicoquímicas realizadas antes e depois dos tratamentos. Em resposta a análise de condutividade os três tratamentos apresentaram uma redução na capacidade de conduzir corrente elétrica, tal fato é influenciado pela natureza dos coagulantes e também pela temperatura da solução no momento da medição. O tratamento que obteve maior condutividade foi $\mathrm{o}$ tratamento 3 contendo aloe vera com 2,2 $\mathrm{mS} / \mathrm{cm}$.

$\mathrm{O}$ pH sofreu pequenas variações quando submetido aos diferentes tratamentos, podemos assim inferir que o 
mesmo se apresenta apenas como uma variável qualitativa.

Os resultados obtidos de $\mathrm{O}_{2}$ dissolvido (\%) foram satisfatórios apenas para os tratamentos 1 e $2,19,5 \%$ e $15,4 \%$ de $\mathrm{O}_{2}$, respectivamente. Enquanto que o tratamento 3 apresentou resultado idêntico ao resíduo bruto. $\mathrm{O}$ tratamento 1 contendo cloreto férrico obteve uma maior quantidade de $\mathrm{O}_{2}$ dissolvido.

O resultado da análise de sólidos totais dissolvidos sofreu interferência da grande quantidade de sólidos presentes no resíduo, impossibilitando uma resposta precisa da quantidade de sólidos solúveis nos tratamentos.

Os tratamentos foram submetidos à análise visual, possibilitando a identificação da coloração mais límpida, porém não translúcida no tratamento 2 , contendo sulfato de alumínio, conforme ilustrado na figura 5 .

Tabela 2. Resultados das análises físico-químicas

\begin{tabular}{|c|c|c|c|c|}
\hline Análises & Resíduo bruto & Tratamento 1 & Tratamento 2 & Tratamento 3 \\
\hline Condutividade & $8,63 \mathrm{mS} / \mathrm{cm}$ & $1538 \mathrm{uS} / \mathrm{cm}$ & $705,5 \mathrm{uS} / \mathrm{cm}$ & $2,2 \mathrm{mS} / \mathrm{cm}$ \\
\hline pH & 7,48 & 7,53 & 7,59 & \\
\hline Oxigênio dissolvido & $9,9 \%$ de $\mathrm{O}_{2}$ & $19,5 \%$ de $\mathrm{O}_{2}$ & $15,4 \%$ de $\mathrm{O}_{2}$ & $9,9 \%$ de $\mathrm{O}_{2}$ \\
\hline $\begin{array}{l}\text { Sólido totais } \\
\text { dissolvidos }\end{array}$ & $577 \mathrm{mg} / \mathrm{L}$ & $1126 \mathrm{mg} / \mathrm{L}$ & $449 \mathrm{mg} / \mathrm{L}$ & $1430 \mathrm{mg} / \mathrm{L}$ \\
\hline Coloração & escuro & turva & $\begin{array}{l}\text { límpida mas não } \\
\text { translúcida }\end{array}$ & amarelada \\
\hline Odor & fétido & cloro + acentuado & não fétido & cloro + acentuado \\
\hline Alcalinidade & $\begin{array}{c}427,2 \mathrm{mg} / \mathrm{L} \mathrm{de} \\
\mathrm{CaCO}_{3}\end{array}$ & $\begin{array}{c}106,8 \mathrm{mg} / \mathrm{L} \mathrm{de} \\
\mathrm{CaCO}_{3}\end{array}$ & $106,8 \mathrm{mg} / \mathrm{L}$ de $\mathrm{CaCO}_{3}$ & $\begin{array}{c}106,8 \mathrm{mg} / \mathrm{L} \mathrm{de} \\
\mathrm{CaCO}_{3}\end{array}$ \\
\hline
\end{tabular}

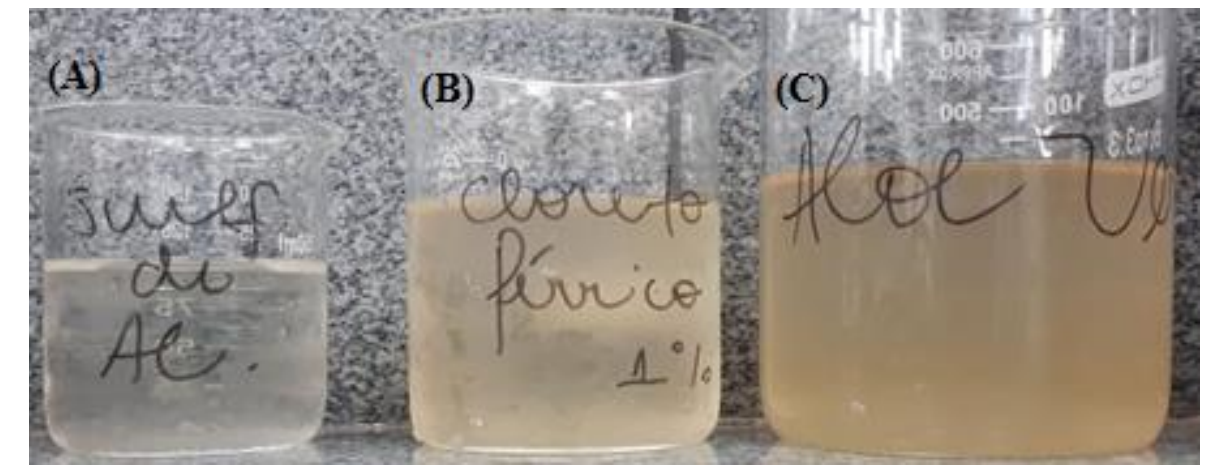

Figura 5- Coloração final das amostras: (A) Sulfato de alumínio; (B) Cloreto férrico; (C) Aloe vera.

O odor característico identificado no resíduo bruto foi imperceptível após os tratamentos. Contudo, nos tratamentos $1 \mathrm{e}$ 3 prevaleceu o odor acentuado de cloro.

Já na análise da alcalinidade podese perceber a diminuição da concentração de $\mathrm{CaCO}_{3}$, passando de $427,2 \mathrm{mg} / \mathrm{L}$ no resíduo bruto para $106,8 \mathrm{mg} / \mathrm{L}$ nos três tratamentos.
A figura 6 apresenta os dados obtidos na análise de cálcio (g). É nítido o acúmulo de cálcio no tratamento 3 , tal fato pode ser justificado pela composição do coagulante natural, totalizando $0,0022 \mathrm{~g}$ de cálcio. Enquanto nos tratamentos 1 e 2 os níveis de cálcio se mantiveram muito próximos ao do resíduo bruto.

O elemento em questão é de grande importância para o desenvolvimento da 
atividade secundária do produtor, uma vez que o mesmo utiliza a fertirrigação nas pastagens, dado que substâncias que contém cálcio são responsáveis por combater a acidez do solo e propiciar um balanço nutricional ideal.

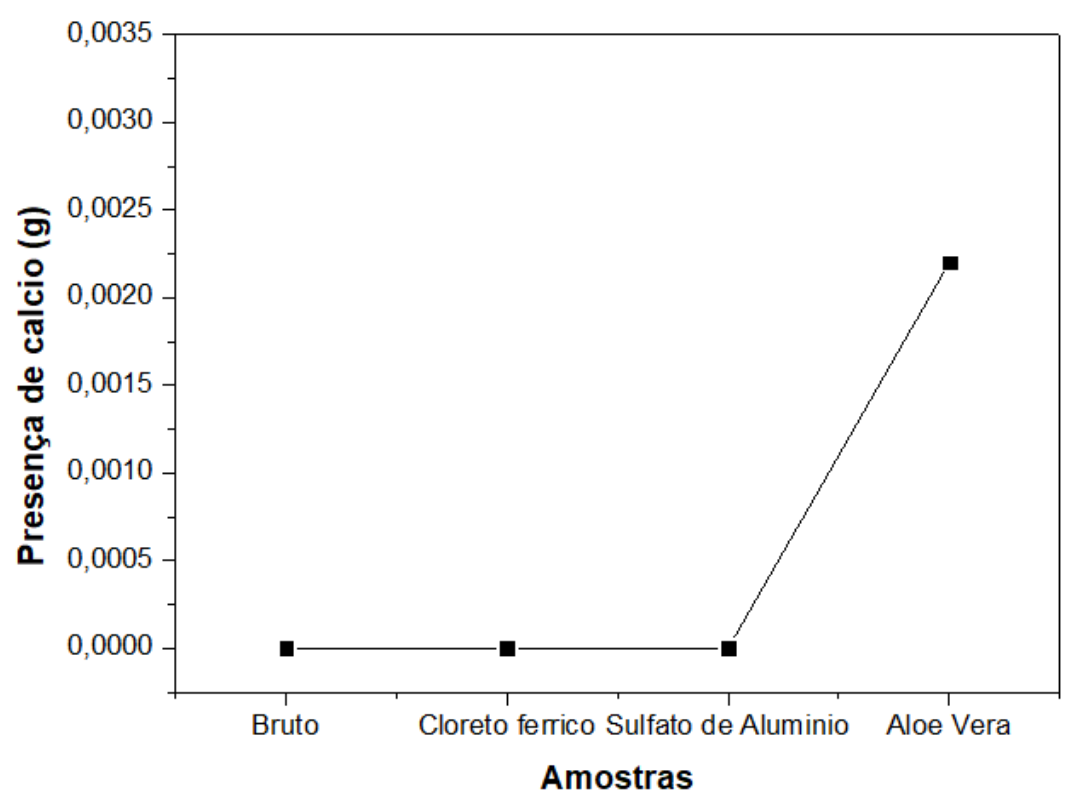

Figura 6 - Análise de cálcio.

A figura 7 expressa os resultados obtidos na análise de concentração de cloretos (mg/L). A concentração de cloretos nos três tratamentos é maior quando comparados com o resíduo bruto, no entanto, entre os tratamentos o que apresentou elevada concentração de cloretos foi o tratamento 1 , contendo cloreto férrico. Tal fato justifica-se pela composição do coagulante químico utilizado ser abundante em cloretos.

A presença deste grupo é de suma importância para os animais de produção. O controle dos níveis de cloretos é necessário para evitar a toxicidade e as deficiências de outros nutrientes devido à concorrência na assimilação de nitrato e sulfato, por exemplo.

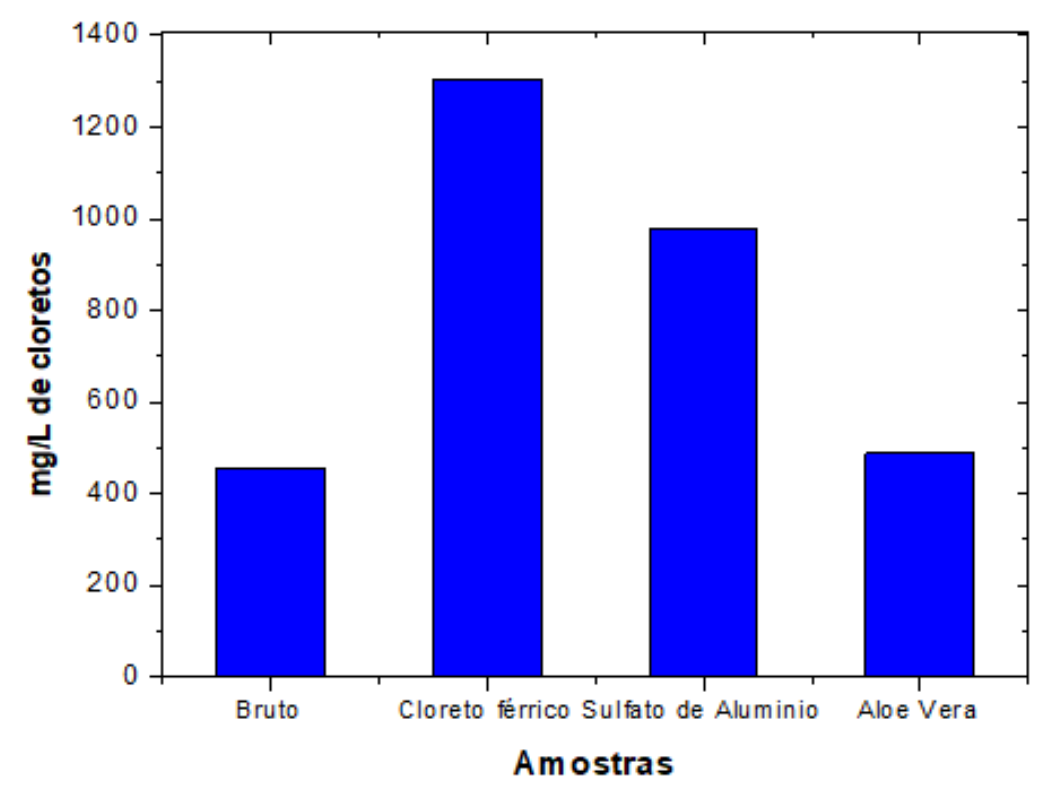


Figura 7 - Análise de cloretos.

A figura 8 apresenta a porcentagem de remoção de DQO (\%).O tratamento 2 apresentou maior eficiência na remoção de DQO, atingindo 85,49\%. Enquanto que os tratamentos 1 e 3 apresentaram $68,52 \%$ e $62,03 \%$, respectivamente. A presente análise evidencia que o tratamento contento sulfato de alumínio contribui para redução da quantidade de oxigênio necessária para a degradação das moléculas orgânicas presente no resíduo.

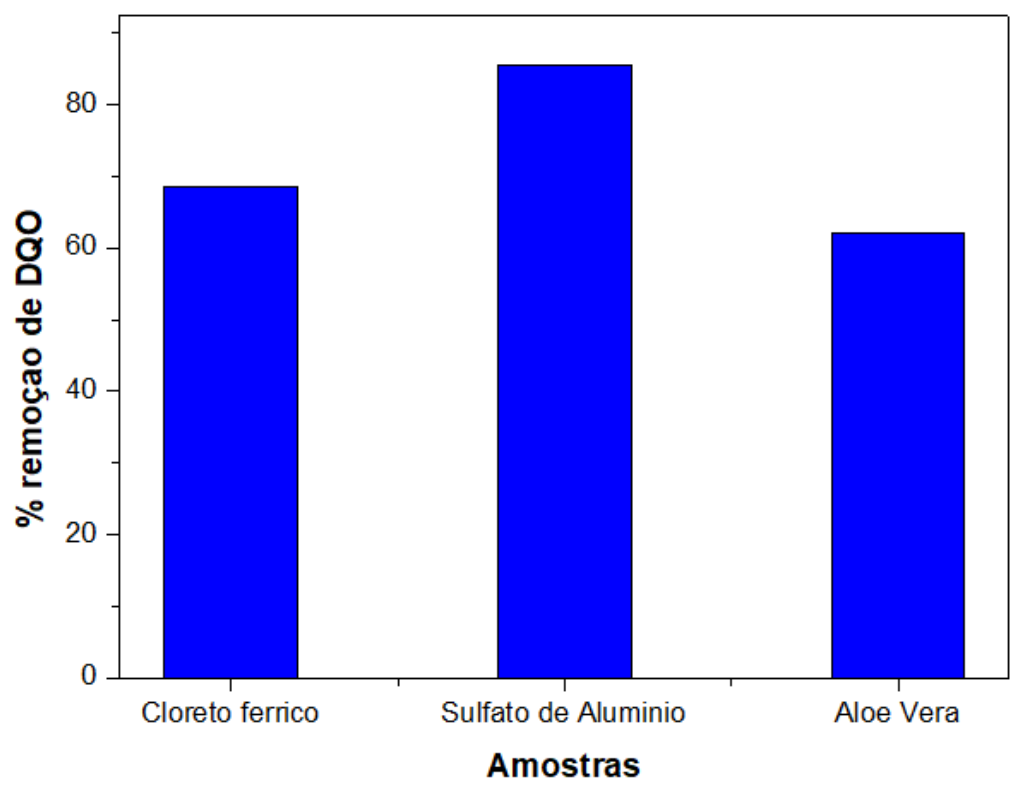

Figura 8- Porcentagem de remoção de DQO.

A figura 9 expressa os resultados obtidos das análises de sódio e potássio pelo método fotométrico de chama $(\mathrm{mg} / \mathrm{L})$.

$\mathrm{Na}$ análise de sódio, o tratamento 2 apresentou a menor concentração em comparação ao resíduo bruto e assim como em relação aos demais tratamentos. Já
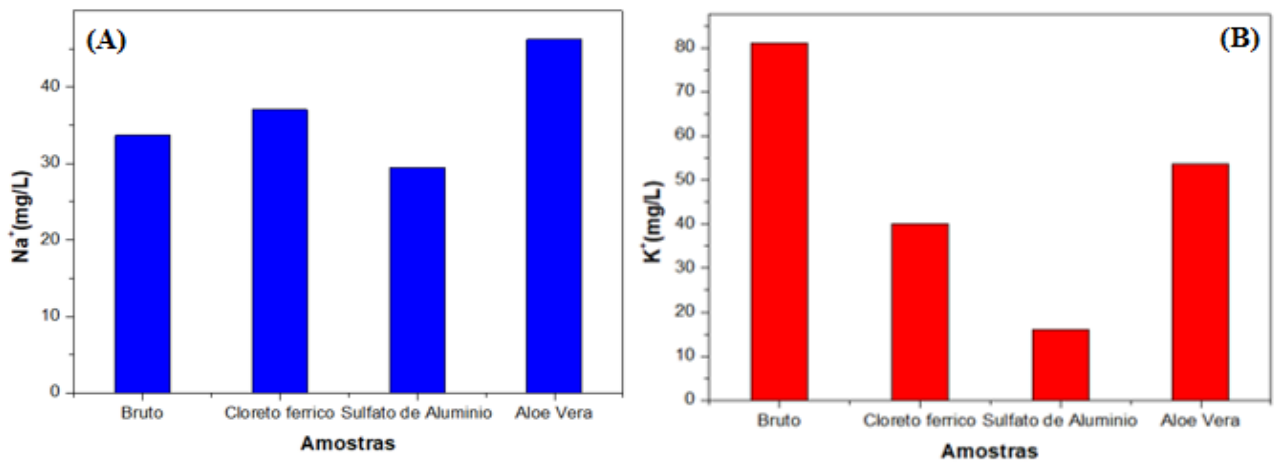

Figura 9 - (A) Análise de Na (B) Análise de K.

Estudos demonstram que pastagens com baixas concentrações de sódio apresentam uma maior palatabilidade, resultando em uma melhor adesão por análise de potássio, todos os tratamentos realizados apresentram redução na concentração do elemento quando comparados com o resíduo bruto. Esse fato pode ser explicado pela retenção de matéria orgânica durante as etapas do tratamento.

parte dos animais, e maior produtividade, dado que a toxicidade por grandes quantidades de sódio afeta a disponibilidade de outros elementos 
podendo causar doenças nos animais. Sendo assim, o tratamento 2 apresenta-se como mais indicado para o suprimento da atividade secundária do produtor.

A presença de potássio é de grande importância para o desenvolvimento das plantas, porém em altas concentrações ele pode causar uma redução na disponibilidade de outros elementos como

\section{CONCLUSÕES}

Os resultados obtidos no presente trabalho demonstraram a eficiência dos tratamentos utilizados, subsidiando informações importantes, principalmente, para a atividade secundária do produtor além de potencializar o desenvolvimento da mesma.

Observa-se que os tratamentos químicos realizados apresentaram uma

\section{REFERÊNCIAS BIBLIOGRÁFICAS}

APHA, AWWA, WEF, (2012), Standard Methods for examination of water and wastewater, Washington $\mathrm{DC}, 22^{\text {nd }}$ ed.

ASTM, American Society for Testing and Materials. Standard test methods for chemical oxygen demand (dichromate oxygen demand) of water, D1252-95, ASTM Annual Book of Standards. American Soc. Testing \& Materials, Philadelphia, Pa, 1995.

CORNICIUC, C. M. O tratamento convencional coagulação/floculação na remoção de nanopartículas metálicas. $2015 . \quad$ Disponível em: $<$ https://sapientia.ualg.pt/bitstream/10400. 1/8314/1/TESE_CCorniciuc.pdf $>$. Acesso em: 16 nov. 2018.

FIORI, M. G. S.; SCHOENHALS, M.; FOLLADOR, F.A.C. Análise da evolução tempo-eficiência de duas composições de resíduos agroindustriais no processo de compostagem aeróbia. Espirito Santo do Pinhal, 2008. Disponível em: < file:///C:/Users/user/Desktop/EA-2008164.pdf>. Acesso em: 19 nov. 2018. cálcio, magnésio, sódio e boro podendo assim comprometer os processos metabólicos durante a época de parição das vacas de cria. $\mathrm{O}$ tratamento 2 é considerado o mais eficiente visando também a atividade secundária do produtor. É importante ressaltar que o balanço sódio:potássio afeta a retenção de água e a desidratação dos animais.

melhor eficiência em comparação ao tratamento com aloe vera, porém o uso de substâncias como cloro em grande quantidade pode tornar o tratamento inviável, dessa forma o tratamento por aloe vera também é bastante satisfatório quando também se leva em consideração o meio ambiente.

GIFFONI, P.O; LANGE, L.C. A. A utilização de borra de fosfato como matéria prima alternativa para a fabricação de tijolos. Engenharia sanitária e ambiental. Vol.10, 2005, p. 128-136. Disponível em http://www.scielo.br/scielo.php?script=sci _arttext\&pid=S141341522005000200006\&lng=pt\&nrm=iso $>$. ISSN 1413-4152. Acesso em: 19 nov. 2018.

IBGE- Instituto Brasileiro de Geografia e Estatística. Suinocultura industrial. 2018. Disponível em: $<$ https://www.suinoculturaindustrial.com.b r/imprensa/com-recorde-historico-brasilabate-4319-milhoes-de-suinos-em2017/20180321-152235-n120> Acesso: 19 nov. 2018.

LAUCENA, M.V.; CHERNICHARO, C.A.L. Avaliação experimental da compostagem de RSU submetidos à etapa previa de tratamento anaeróbio. ln: $23^{\circ}$ Congresso brasileiro de engenharia sanitária. Anais. Campo grande, 2005. 
LUDTKE, C. B.; CIOCCA, J. R. P.; DANDIN, T.; BARBALHO, P. C.; VILELA, J. A.; COSTA, O. A. D. Abate humanitário de suínos. Rio de Janeiro: WSPA, 2010. Disponível em:< http://www.agricultura.gov.br/assuntos/boa s-praticas-e-bem-estar-animal/arquivospublicacoes-bem-estar-animal/programasteps-abate-humanitario-de-suinos.pdf $>$. Acesso em: 19 nov. 2018.

MIELE, M., SANDI, J. A. Custos de produção, câmbio e competitividade da suinocultura brasileira a partir dos dados da rede InterPIG. Embrapa Suínos e Aves. 2016. Disponível em:< https://www.embrapa.br/documents/ 1355242/9156138/Artigo+CIAS++ Custos+de+produ\%C3\% A7\%C3\%A3o\% 2C\%20c\%C3\%A2mbio+e+competitividad e+da+suinocultura+brasileira+a+partir+do s+dados+da+rede+InterPIG.pdf/92c74319ccab-4f35-8295-440c92db8bc0> Acesso: 19 nov. 2018.

SANTOS, F. A. Bem-estar dos suínos. Revista Eletrônica Nutritime, v. 1, n. 3, p. 101-116, nov.-dez. 2004.

STRAUS, E. L.; MENEZES, L.V.T. Minimização de resíduos. $\ln : 17$ Congresso Brasileiro de Engenharia Sanitária e Ambiental, Anais, p. 212-225, 1993.

VESILIND, P. A.; MORGAN, S. M. Introdução à Engenharia Ambiental. Cengage Learning. 2011. 